\title{
1 Challenges to link climate change data provision and 2 user needs - perspective from the COST-Action VALUE
}

3

Short title: Challenges to link climate change data provision and user needs

Roessler $\mathrm{O}^{1}$, Fischer $\mathrm{AM}^{2}$, Huebener $\mathrm{H}^{3}$, Maraun $\mathrm{D}^{4}$, Benestad $\mathrm{R}^{5}$, Christodoulides $\mathrm{P}^{6}$, Soares $\mathrm{PMM}^{7}$, Cardoso $\mathrm{RM}^{7}$, Pagé $\mathrm{Ch}^{8}$, Kanamaru $\mathrm{H}^{9}$, Kreienkamp $F^{10}$, Vlachogiannis $D^{11}$

(1) Oeschger Centre of Climate Change Research, Institute for Geography, University of Bern, Switzerland (ole.roessler@giub.unibe.ch), Hallerstrasse 12, 3012 Bern, Switzerland, Tel: 004131618017, Fax: 004131618511

(2) Federal Office of Meteorology and Climatology, MeteoSwiss, Zurich, Switzerland

(3) Hessian Agency for Nature conservation, Environment and Geology, Germany

(4) Wegener Center for Climate and Global Change, Uni Graz, Austria

(5) The Norwegian Meteorological Institute, Norway

(6) Faculty of Engineering and Technology, Cyprus University of Technology, Limassol, Cyprus

(7) Instituto Dom Luiz, Faculdade de Ciências, Universidade de Lisboa, Portugal

(8) CERFACS, Toulouse, France

(9) FAO, Rome, Italy

(10) Deutscher Wetterdienst, Potsdam, Germany

(11) Environmental Research Laboratory, INRASTES, NCSR "DEMOKRITOS", Greece 
31 Challenges to link climate change data provision and user needs - perspective from the COST-Action VALUE

The application of climate change impact assessment (CCIA) studies in general and especially the linkages between different actor groups typically involved is often not trivial and subject to many limitations and uncertainties. Disciplinary issues like competing downscaling approaches, imperfect climate and impact model data and uncertainty propagation as well as the selection of appropriate data sets are only one part of the story. Interdisciplinary and transdisciplinary challenges add to these, as climate data and impact model data provision and their usage require at least a minimum of common work and shared understanding among actors. Here, we provide the VALUE perspective on current disciplinary challenges and limitations at the downscaling interface and elaborate transdisciplinary issues that hamper a proper working downscaling interface. The perspective is partly based on a survey on user needs of downscaled data that was distributed among 62 participants across Europe involving 22 sectors. Partly, it is based on the exchanges and experiences gained during the lifetime of VALUE that brought together different actor groups of different disciplines together: climate modelers, impact modelers, statisticians, and stakeholders. We outline a sketch that summarizes the linkages between the main identified actor groups: climate model data providers, impact modelers and societal users. We summarize and structure current actors groups, needs, and issues. We argue that this structuring enables involved actors to tackle these issues in a more organised and hence effective way. A key solution to several difficulties at the downscaling interface is to our 
Roessler et al. Challenges to link climate change data provision and user needs

54 framework. In addition, fostering communication between actor groups - and financing this communication - is essential to obtain the best possible CCIA as a prerequisite for robust adaptation.

Keywords: downscaling, user needs, climate services, climate change, VALUE

\section{Introduction}

The Earth's climate is not stable over time. Natural influences have changed the Earth's climate regularly in the past. The growing anthropogenic changes of atmospheric greenhouse gas and aerosol concentrations and man-made land use changes have modified the climate over the last decades and will likely continue to do so over the coming century (Intergovernmental Panel on Climate Change 2014). In fact, even in the presence of drastic mitigation measures, the inertia of the climate system inevitably leads to further warming over the next decades, and the Earth's temperature is expected to increase at least by one-and-a-half degrees, compared to preindustrial conditions, provided that the enfolding UNFCCC COP21 agreement is implemented. Hence, robust Climate Change Impact Assessment studies (CCIA) are - among others - an important cornerstone to assess the vulnerability of a given system (i.e. impact on natural systems, society and economy) and to develop adaptation strategies in a reliable manner. Even more, the comprehension and visualization of possible impacts of climate change can enforce the willingness for mitigation and adaption in everyday-business. Today's central importance of CCIA finds its expression not only by the vast number of research projects that have been accomplished in this field, but also in the demand of the society, authorities and institutions, as 
Roessler et al. Challenges to link climate change data provision and user needs

well as the private sector (e.g., (re-)insurance companies) to receive answers to climate change related questions (Field et al. 2014).

Despite its relevance and wide usage, the application of CCIA in general and especially the linkages between different actor groups typically involved is often not-trivial and subject to many limitations and uncertainties. As most of the users are experts on their own topic, but not necessarily on climate or climate model data, they are often unsure about the data origin, data access, data appropriateness, data reliability and quality, correct usage of data, and what kind of information can be drawn from them. We here refer to climate data users as the community of researchers, administrations, environmental consultants, experts from private companies like insurance, policy advisors or NGOs, in line with the definition of the IS-ENES initiative (Swart and Avelar 2011). In contrast, climate data providers generate and provide climate data or derive information out of it.

CCIA typically rely on projections from global climate models, i.e., coupled ocean - atmosphere general circulation models that are further downscaled by dynamical or statistical downscaling models (Maraun et al. 2010; Rummukainen 2010) to provide local-to-regional information for driving impact models or to derive local scale climate information. Hence, the quality of the climate data and its local-to-regional derivate becomes critical. Climate data providers operate from a position of trust. They need to consider the consequences of their actions and provided information. If not, poor decision-making and maladaptation may occur with potentially large costs at a later stage. Hewitson et al. (2014) argue that any type of climate model output to be used in a decision making context needs to be plausible, defensible and actionable. McNie (2007) defined a theoretical basis for "useful data", and proposed following Cash and Clark (2002) that data should be salient, credible and legitimate. 
Roessler et al. Challenges to link climate change data provision and user needs

Given these high expectations, how can one guarantee to provide the best quality climate model data available this is still an open issue. The challenge lies in the multitude of aspects to conside : data availability and quality, the quality of the climate models, the kind of data user request, and the downscaling method (if applied). With respect to downscaling, numerous techniques are known today and their skills have been evaluated in several case studies as well as intercomparison projects (Goodess 2005; Christensen and Christensen 2007; Benestad et al. 2008; van der Linden and Mitchell 2009; Maraun et al. 2010; Nikulin et al. 2015). The EU COST Action VALUE has developed a comprehensive framework to systematically intercompare different downscaling approaches for climate change applications (Maraun et al. 2015). The first results of this most comprehensive benchmark test are published in this journal issue. From the perspective of a climate data user, similar challenges exist as for the providers: one needs to select the most appropriate data from a variety of possibilities to best suit a given project. Over recent years, a variety of projects and portals have put effort in providing data set to users, e.g. ENSEMBLES, CORDEX, CMIP5, ClipC, IS-ENES, climate4impact, to name a few. In addition, numerous smaller, national or institutional data set exist (see Table 1), not speaking about further individual data sets. The archived data typically stem from several climate model simulations, be it Regional Climate Model (RCM) or Global Climate Model (GCM) data, cover the effects of different emission scenarios and provide a wide range of applicable atmospheric variables. This easy accessibility is generally very welcomed and commendable for all different kinds of disciplines. However, from a user perspective, it prompts the some practical questions on data selection: which emission scenarios to choose, how many ensemble members to apply, which climate model represents my location of interest best, and which climate model variables 
Roessler et al. Challenges to link climate change data provision and user needs

can be judged trustworthy. In the view of Barsugli et al. (2013), the "practitioner's dilemma" is no longer the lack of downscaled projections; it is how to choose an appropriate data set, assess its credibility, and use it wisely.

However, disciplinary issues as discussed above are only one part of the story. Interdisciplinary and transdisciplinary challenges add to these, as climate data provision and its usage require at least a minimum of collaborative work. With "interdisciplinary" we mean the exchange of knowledge and methods between different scientific disciplines for the goal of new emerging scientific knowledge. By "transdisciplinary", we understand in line with Bergmann et al. (2012) the "research process" that involves "societal actors with practical knowledge" and "problemappropriate scientific disciplines" to answer "real-world problems scientifically". A crucial part in transdisciplinary approaches is the definition of a common framework, a common language, and mutual learning.

The downscaling interface on the whole is thus subject to challenges of disciplinary, interdisciplinary and transdisciplinary matter. In Europe, some of these challenges have been recognized and tackled within the EU COST Action VALUE by bringing together the providers and users of climate information and thereby bridging the gaps between scientists, stakeholders, and statisticians. The main goal of VALUE is to provide a web-based validation portal to enable an objective selection of downscaling methods, and to guide users to those localized data that best fit their CCIA. To develop guidance, the needs of the users were first investigated. This included an European-wide user survey accompanied by a review of already existing studies.

The current paper is not meant as a review paper, but provides the perspective and displays the experiences of the VALUE network about user needs and challenges currently present at the 
Roessler et al. Challenges to link climate change data provision and user needs

downscaling interface. A basic assumption in this paper is that the downscaling interface is currently working improperly. Although several positive CCIA examples can be found in the literature (Snäll et al. 2009; Etzelmüller et al. 2011; Addor et al. 2014; Hansen et al. 2014), they are not common practice. The consequences can be found in many projects that - at least in our opinion appraisal - either use falsely downscaled data, apply suboptimal methods, or draw wrong conclusion from the data. The aim here is therefore to elaborate why the downscaling interface works imperfectly and to suggest possible ways to improve it. First, we define the actor groups involved at the climate data provision-usage interface and suggest a structure of this interface. Thereafter, we concentrate on the user needs as found by our survey and by a literature review of user needs in Europe. These needs are confronted with current possibilities and limitations of climate data providers resulting in a conclusion of current scientific gaps. We then add to these scientific challenges and limitations several non-scientific issues that hinder a better linkage at the downscaling interface. Doing so, we summarize possible ways to tackle the current gaps and conclude.

\section{Actor Groups at the Downscaling Interface}

A first essential step to overcome limitations at the downscaling interface is an inventory of actors, their functions and their background. This structuring helps to organize and assign current challenges and to tackle these challenges in a structured way. In the following, we present a concept of how the members of the VALUE project experience and perceive the downscaling interface. Three different actor groups - being climate data providers, impact modellers and societal users are interacting at the climate data - user interface. To illustrate the disciplinary, interdisciplinary and transdisciplinary interactions, we provide a sketch of the 
Roessler et al. Challenges to link climate change data provision and user needs

constellation of these actors and their interactions (Figure 1). We refer to "climatologists" (purple colour) as scientist who develop and apply climate models (global or regional) or postprocess and analyse their results from a meteorological or climatological perspective. These groups make up what we call the "data providers." "Impact modellers" (green colour) are the vast group of researchers, consultants, and other modellers that use the climate data in their specific model to derive climate change impact scenarios in their field of experience. They are mainly interested in the usage of the climate data. "Societal users" (red colour) are users that articulate their specific needs and make decisions, which are derived from everyday experiences and local expert knowledge. The needs can be identified together with climate and related impact information from both other actor groups. This general grouping needs to be specified twofold: First, all three actor groups can recruit from different sectors (stripes, Figure 1), be it research, administration, the private sector or consultancies, and hence each actor group has its own characteristics of involved people. The exception is the lack of research sector by definition in the actor group of societal users. Second, each actor group is subdivided into 1 st and 2 nd order actors, with the 1st order actors being directly involved at the linkage and the 2 nd order actors being the framing community of each actor group. 
Roessler et al. Challenges to link climate change data provision and user needs

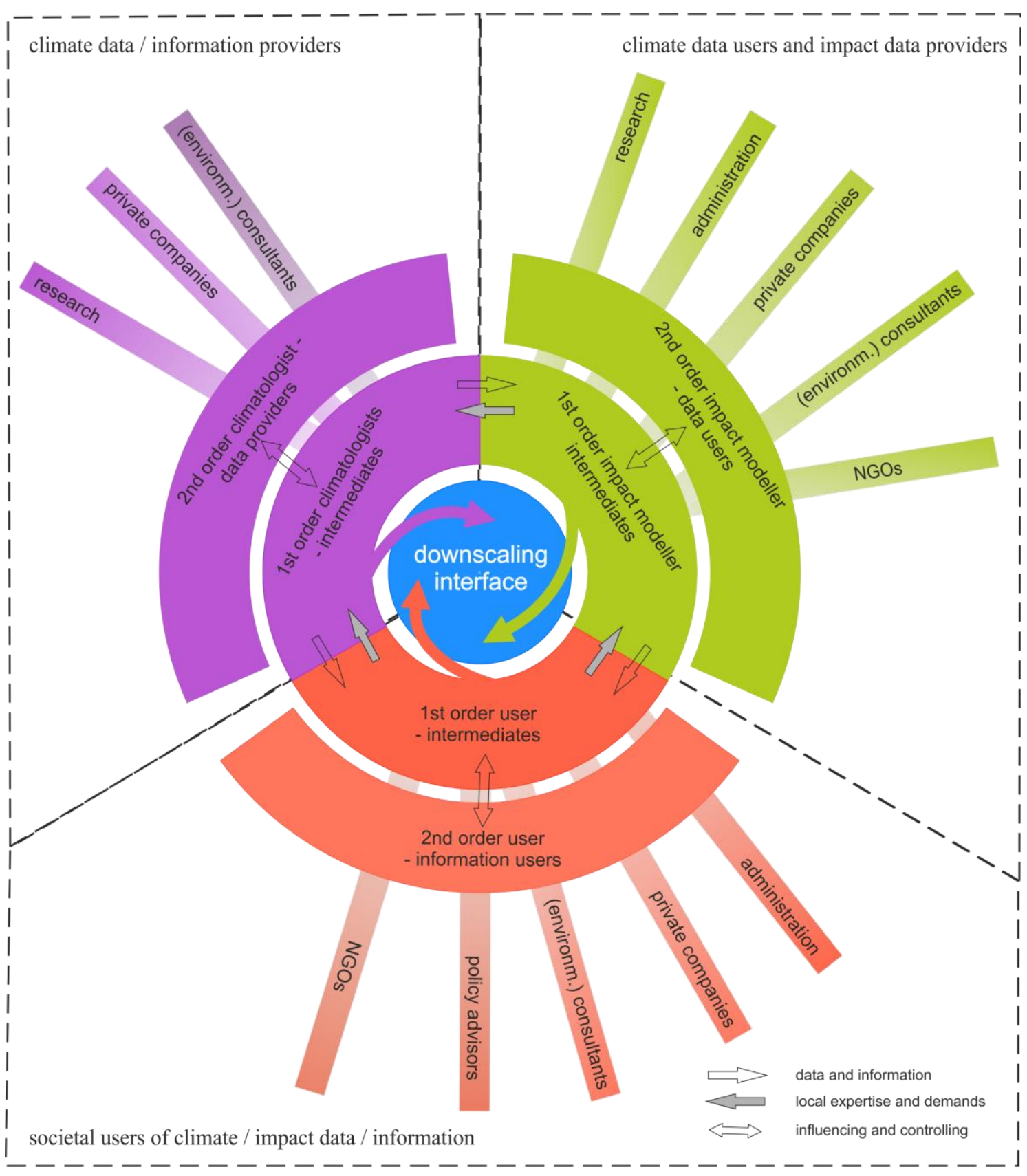

Figure 1: Constellation of actors at the downscaling interface, illustrating the transdisciplinary setting, the different sectors actors may recruit from, as well as the main perspective the actors have on the data/information.

189 1st order actors refer to the group "intermediaries" in other projects like ClipC (Groot et al. 2014) 
Roessler et al. Challenges to link climate change data provision and user needs

conceptualization, as we value the "origin" of an actor higher than their function at the downscaling interface. An example to explain this weighting is the following: a climatologist will still perceive problems, advice and act with a perception of a climatologist, and perception of challenges at the downscaling interface differ among all actor groups. 2nd order actors are climate modellers, impact modellers or societal users that either generate the climate data to be downscaled, make use of other impact results, or receive information from societal users without any direct contact to actors from the other groups. These framing actors are important as they also influence the demands and needs articulated from the 1st order actors (societal users and impact modellers) or have a community based controlling function. In our constellation of actors, 2 nd order actors are not interacting with actors from the other two segments but communicate solely via the 1st order actors. As not only different scientific disciplines but also different non-scientific sectors are involved, the downscaling interface is clearly a transdisciplinary setting.

To make this theoretical outline more palpable, we give an example concerning a real-case adaptation measure in Switzerland: With the expected future increase in dry periods in summer over Switzerland, the water level of the river Rhine in Basel, Switzerland, may fall below a critical threshold, so that the shipping capacity may be endangered. To circumvent this climate-related risk, a deepening of the river bed is discussed as one potential measure. This however, comes at the expense of having potential negative implications on the ecosystem. To perform a robust analysis of potential, quantified impacts that justifies and enables this adaptation measure, many actors need to get involved: 
Roessler et al. Challenges to link climate change data provision and user needs

212 (a) 1st order climatologist: this may be a scientist who applies a certain downscaling method

213 (e.g. a bias-correction method) to the output of a multi-model ensemble (e.g. from CORDEX)

214 resulting in daily transient scenario data for several locations in the Rhine catchment.

215 (b) 1st order impact modeller: a hydrologist who uses these data as input for their specific

216 hydrological model and analyses the impacts on runoff low flows in Basel.

217 (c) 1st order user: a representative of the water department of the local authorities. They inform

218 the impact modeller what the critical levels of water flow are and what this means in terms of

219 transport capacity. Furthermore, they bring in the knowledge of what negative impacts are to

220 be expected to aquatic ecology from an intervention of the river bed.

221 (d) 2 nd order climatologist: e.g. someone from the climate community who is predominantly

222 interested in the method on how to generate local scenario data. They interact with the 1st

223 order climatologist to suggest a particular improvement of their downscaling method and the

224 selection of specific climate model ensembles.

225 (e) 2nd order impact modellers, e.g. someone from the hydrological model community,

226 discussing, advising and controlling the 1st order modeller in terms of model type, model set up,

227 and parameter estimation. It might also be someone who performs similar analyses but for other

228 catchments.

229 (f) 2nd order user: e.g. someone from the local and regional authority, who makes decisions on

230 the measures to implement. The decision is based on the advisory of 1st order user. A 2nd order

231 user might also be someone from the water division at the federal level who is concerned with

232 the same question but at different locations. They call for a comprehensive risk analysis taking

233 into account all hotspots of reduced shipping capacity that may be in danger over Switzerland. 
Roessler et al. Challenges to link climate change data provision and user needs

The above example clearly illustrates the depiction shown in Figure 1 as follows: There is an inner circle of actors with scientific and non-scientific backgrounds that is actively shaping the downscaling interface. E.g., they decide which data, models, methods and thresholds to apply today and in which direction science do research. Direct interactions among the 2 nd order actors are missing. They influence however the process via influencing the 1st order actors in a transdisciplinary setting.

\section{What do users of climate data need? Results from surveys}

Based on the idealized conceptualization above, we question whether there are specific needs of each user group and if and how climate providers can meet these expectations. For sure, the needs differ not only between the users groups, but also between the different sectors the users work in. In addition, the user needs are likely related to their specific knowledge with respect to the processing or handling of downscaled climate data. Over and above this, our experiences are completely in line with statements by colleagues that there is not the one user, but every specific user has their own needs that drives the foresight itself (Cuhls 2003). Still, we argue that some more general needs can be extracted from literature, experiences, or surveys. Even more, an overview of general needs is essential to give data providers some guidance and to elucidate how user needs and climatological offers match.

\subsection{The survey of the VALUE initiative}

Specific user needs have been gathered by several surveys in various countries, e.g. Austria (Formayer et al. 2011), Finland (Haanpää et al. 2009), and recently Switzerland (MeteoSwiss 
Roessler et al. Challenges to link climate change data provision and user needs

2016). Furthermore, at least two European projects compiled an overview of user needs, extracted from other project reports: IS-ENES project (Swart and Avelar 2011), the ClipC initiative (Groot et al. 2014), and EUPORIAS project (Hewitt et al. 2013). Within VALUE, we also conducted a survey on user expectations on downscaling data in general and their needs in specific. We distributed a questionnaire among the VALUE participants to approach experts from their country or network, both from science and the non-science sector. 62 experts from all parts of Europe and different CCIA sectors responded. In total 26 questions were asked about user's key variables, their temporal and spatial structure, accuracy needed, data structure (time series vs. probability density functions), the type of intended application as well as the background of the user. Here, we present the main findings of this survey and set them into context of the many different surveys conducted in Europe. Most participants (39) called themselves "impact modellers" (72\% of all answers; please note that 8 participants skipped the question), 5 decision makers (9.3\%), 5 consultants (9.3\%) and 5 found themselves to belong to another group (9.3\%), with most participants from the hydrology sector $(60 \%)$. This clearly shows a bias in the participant structure in terms of sector (water), and in terms of working environment (most participants are from academia). All the responses shown below were hence controlled by this strong bias, by differentiating the results between the answers of all participants and the non-hydrologists and impact modellers, respectively. Table 2 summarizes some results of the VALUE questionnaire based on all 62 responses and those results obtained from the underrepresented group ( $n=12$, blue values).

The two key variables for all users were unsurprisingly precipitation and temperature, followed by wind, radiation, and humidity. This ranking is irrespective of the kind of user and probably might refer back to the usage of energy-balance equations, or their potential to cause 
Roessler et al. Challenges to link climate change data provision and user needs

catastrophic extremes like heat waves, floods and droughts, and wind gusts. Most impact modellers are in favour of daily and hourly data at the point scale and require high spatial resolution. All other users agree in preferring daily data but are also interested in aggregated values over a region. The accuracy needed for all key variables fluctuates depended on the respective parameter, but $+/-10-20 \%$ are widely accepted. The high accuracy required constitutes a challenge to current climate model data and downscaling techniques. We also asked for the lowest accuracy the user can still work with and found only a very slight increase in tolerance. Interestingly, a significant part of users was sure of what kind of data they need, but were unsure about their temporal, spatial resolution or accuracy.

Generally speaking, the survey showed that impact modellers basically demand climate model data that has the same characteristics as observations. This make sense as they use observed records to calibrate their models and the projected climate data are therefore requested to be as similar to observed climate data as possible: i.e., time series as absolute values with "correct" representation of mean values, intensity, frequency, day-to-day variability and extremes. In terms of the data associated uncertainties and uncertainty bands, users (decision makers even more than impact modellers) believe that they conceptually understand what uncertainties are, but handling of uncertainties is diverse or partly unclear. Groot et al. (2004) put this selfappraisal into a different light by showing that the concept of uncertainty is different for the various actor groups and, partly, even more a phrase than a concept.

The results of the VALUE survey in principle confirms previous studies in terms of key variables and their resolution. However, our survey misses the importance of climate indices for many users, as e.g. highlighted by the synthesis report of the ClipC project (Groot et al. 2014). Swart and Avelar (2011) even find that the first product for every user are climate indices, based on 
Roessler et al. Challenges to link climate change data provision and user needs

which additional data can be chosen. This deviation of findings may originate in the fact that the cited surveys are based on merely societal user responses, whereas our main responses come from impact modellers that have a long history in working with meteorological input time-series.

\subsection{Overview of other surveys conducted}

As part of VALUE a review of national surveys or experiences has been compiled and personal experiences from several European countries were gathered (Benestad et al. 2014). This comprehensive overview basically underpins the findings of our survey, but also adds some further aspects: besides climate data and climate indices, derivatives of climate data such as snow depth or snow water equivalent have been requested. In addition, numerous interviewees demanded information about flood zones of a community under climate change, land falling tropical storms, hail storms or 10 min rainfall intensity extremes. These very specific demands nicely illustrate a problem in user surveys: An impression on the ICCS2 conference (Pingel 2012) was that user surveys are considered more as a wish-list than a list of absolutely necessary information. It furthermore shows some unawareness of relevant or available data that in turn might lead climate data providers to the impression that users "don't know what they want, but want everything" (quoting: D. Jacob). External surveys also highlight the importance of consistency in space, time, and inter-variable dependencies - a claim that refers back to the statement above that data should be as close to the observation data as possible.

Our review not only revealed which data or information is needed, but also how these should be presented or disseminated. Again, we found strong differences with respect to the user groups: to give a broad overview of the heterogeneity, societal users like decision makers and program initiators may need regional climate projection information on a single page (see ICCS2 
Roessler et al. Challenges to link climate change data provision and user needs

impression, Pingel, 2012), aggregated in an understandable way, e.g. graphics or maps. In Figure 1 we thus distinguish between data relevant for impact modellers and (data derived) information crucial for the societal users. Déandreis et al. (2014) furthermore highlight that climate information might not only be provided via data files, be it raw data or indices, but also via statistics, plots, and maps. Natural science impact modellers in turn need the "raw climate data" (cp. Figure 1) in a way they are familiar with (time-series of station data or regional data, IMPACT2C (http://impact2c.hzg.de/). By "raw climate data" they mostly understand climate model data as close to the raw data as possible, but bias corrected and downscaled to their region of interest. Users from the economic research or users from the private sector typically need information about changes in the impacts (heat waves, floods, wind damages, etc.), and are often satisfied with (regional) changes in the occurrence probability of the impacts - either from the climatological community or from the impact modelling community.

\section{Challenges at the Downscaling Interface}

\subsection{Limitations in Climate Model Data Provision}

The large list of requested variables can be summarized in the general need to obtain future weather data in consistency with climate model projections. With future weather data we mean climate model data, simulated under assumed future forcing conditions, at very high spatiotemporal resolution (ideally as gridded data) with the full set of weather-relevant atmospheric variables. These data are physically consistent in time, space and between variables, contain the relevant uncertainties from climate models, contain extremes not observed so far and contain different evolutions over time. The data should come in a format, so that it is "application- 
Roessler et al. Challenges to link climate change data provision and user needs

ready". How far are we to meet this demand from the perspective of a climate data provider? A number of limitations and challenges have to be considered in this context:

First, one needs to be aware that climate models are, fundamentally, a simplification of nature and therefore, by definition, cannot perfectly reproduce all aspects of the climate system (Räisänen 2007; Randall et al. 2007). Limited technical resources define a maximum complexity of the models in use. This concerns the model's resolution in space and time and hence the number of processes that are explicitly resolved. Atmospheric processes that are not explicitly resolved need to be parameterized (e.g. cloud formation, radiation, aerosol interactions). Some of the processes, such as climate change impacts on vegetation distribution or chemical interactions, are even completely neglected. Finally, even though certain processes might be simulated by the climate models, they might be prone to substantial biases (Flato et al. 2013; Wang et al. 2014). Errors in global climate models are in general inherited by regional climate models (Hall 2014). Furthermore, the nesting of RCMs within GCMs may involve using different ways to parameterise sub-grid processes at the RCM and the GCM levels, which may give rise to physical inconsistencies. Furthermore, RCMs often produce a different precipitation climate (often due to more detailed topography) which implies that the surface evaporation, energy and mass flows, and condensation aloft differ between the RCM and the GCM, and may result in different fluxes of longwave radiation leaving the top of the atmosphere for the two models.

These biases are to a large degree related to the coarse resolution of the climate models. Current generation GCMs from CMIP5 come at a horizontal resolution of $100-300 \mathrm{~km}$, which is too coarse for many applications, in particular over complex terrain. These models generally provide a good representation of many large-scale climate phenomena and their response to climate change, but often fail to represent regional climate characteristics and changes thereof (Zubler 
Roessler et al. Challenges to link climate change data provision and user needs

et al. 2015). For example, while the knowledge about the thermodynamic response to greenhouse gas forcing is robust, the dynamical response (e.g. planetary waves, polar jet streams, and mid-latitude storm tracks) is still not well constrained, giving rise to substantial uncertainty of the regional climate projections (Woollings 2010; Shepherd 2014). Furthermore, the greenhouse effect and the hydrological cycle are connected through common aspects such as atmospheric humidity and clouds (Benestad 2016), and the latter may be more difficult to represent in a GCM.

To better capture regional climate features, regional climate models (RCMs) at a higher spatial resolution are increasingly used as a downscaling tool (Giorgi and Bates 1989; Christensen and Christensen 2007; van der Linden and Mitchell 2009; Rummukainen 2010) . RCMs, such as those from the CORDEX initiative (Giorgi et al. 2009), currently provide a horizontal resolution of about $12.5 \mathrm{~km}\left(0.11^{\circ}\right)$. This kind of simulations add value to LBCs (lateral boundary conditions) in various situations (Feser et al. 2011; Di Luca et al. 2015; Prein et al. 2015) although not for all regions (Di Luca et al. 2013) or at all time scales (added value is diluted when temporal averages are performed; (Kotlarski et al. 2014)). Yet, errors or limitations from the driving LBCs are inherited (Laprise et al. 2008; Hall 2014). Moreover, the resolution is still too coarse to explicitly resolve a number of important processes, such as convection and local thermal circulations. The misrepresentation of convection in RCMs has been suggested to be a major factor for the underestimation of high-intensity precipitation events (Frei et al. 2006; Boberg et al. 2009; Prein et al. 2015) and the failure in correctly reproducing the diurnal cycle of precipitation and other variables (Brockhaus et al. 2008). Even more important, there is evidence that models which parameterise deep convection may substantially misrepresent the response of summertime convective precipitation extremes to global warming (Kendon et al. 2014; Ban et al. 2015; 
Roessler et al. Challenges to link climate change data provision and user needs

393

394

395

396

397

398

399

400

401

402

403

404

405

406

407

408

409

410

411

412

413

414

415

Meredith et al. 2015). Given these serious limitations on the sub-daily scale, hourly data (let alone shorter granularity) can most often not be delivered to users with scientific integrity. Higher resolution convection permitting simulations are required to correctly represent subdaily convective precipitation extremes in models (Kendon et al. 2014; Ban et al. 2015). However, this is still a field of research that has only recently being initiated, due to large computational costs (Prein et al. 2015). Another source of RCM bias, besides the spatio-temporal resolution, is related to the vegetation prescription. State-of-the-art RCMs are usually run with static vegetation, where land use changes are not considered. Yet, Noblet-Ducoudré et al. (2012) demonstrated that regional impacts from land use changes can be at least as important as greenhouse gas forcings although biophysical feedbacks on regional climate are still uncertain in magnitude and sign. Multi-model simulations of land-use changes are still in their infancy although robust information is needed to aid land management decisions.

To circumvent biases and resolve the scale discrepancy between coarse resolved climate model output and the local scale, statistical downscaling methods come into play. These methods establish statistical links between large-scale and observed local-scale weather (Benestad et al. 2008; Maraun et al. 2010; Takayabu et al. 2016). Over recent years a vast number of different statistical downscaling methods have been put forward, each with its own capabilities and limitations regarding different aspects of local daily data: e.g. representation of the multi-variate structure, temporal structure, spatial consistency, variability and extremes.

A cornerstone for the future development of improved climate models and statistical downscaling methods - and hence downscaled data that better match the needs from the user community - is the availability of high-quality observations. Observations are essential to validate and calibrate dynamical models and indispensable to statistically downscale climate 
Roessler et al. Challenges to link climate change data provision and user needs

model data. Ideally, observations reach as far back in time as possible, but at least 30 years must be covered to build reliable statistics thereof. Although extensive meteorological observational datasets are available in Europe today (ECA\&D, EOBS), some regions still lack appropriate observational data sets that give rise to uncertainty. Often, the station network is too sparse to capture the high spatial local variability and the data are not homogenized accounting for station re-locations over the time-span of the measurements. In some cases, high-quality data are available, but the access to the data is either strongly restricted or it involves very high costs. Especially for private companies or consultancies the costs are high and, hence, they even obscure the use of the data. The emergence of high resolution free observational climate databases also contribute to confound the users since very little quality assessment has been performed and for some areas they are completely inaccurate (Bedia et al. 2013).

The access to freely available climate data is often not an issue with climate model data. Consortiums like PRUDENCE, ENSEMBLES and currently CORDEX have provided some extensive data sets that are also available for commercial use. However, to provide local climate information based on these multi-model initiatives also require observations to often either bias-correct the model data or to establish the statistical downscaling link. An open data policy for observational climate data sets would strongly foster this development (e.g. MET Norway). It is of hope that the current international activities with the establishment of global, regional and national climate service centres and data-webportals (e.g. ClipC or Copernicus Climate Change Service) recognize this important need and provides ways to tackle it.

One challenge to bridge the gap between users and providers in terms of climate data provision are the different perspectives of the two groups. Climate data providers have the desire to provide only data that can be disseminated on a sound scientific fundament, while impact 
Roessler et al. Challenges to link climate change data provision and user needs

modellers have the desire to obtain as much data/information as possible to drive their models. Therefore, the two groups need to discuss, even if it is with less confidence, which kind of data can be provided by the data providers to help the impact modellers along. On the other hand, it should be discussed what kind of data might be not perfect but still better than nothing for the impact modellers. In the end, there is a trade-off between providing data that is requested, even though it might not have the highest reliability, and not providing it and let the impact modellers fend for themselves (and perhaps produce a data set themselves that is even less sophisticated than what we could provide). This line has to be negotiated continuously between the two actor groups, because as research develops the line might shift. The limitations described in this section clearly indicate that the general users wish for a future weather is far from being realisable. This in turn strengthen the need for truly tailored regional climate data products that help to achieve at least some aspects of the user needs. At the same time, climate model data need not to get overloaded by users expectations, as in practice only a limited amount of processes, variables and aspects will be relevant in a specific context (Maraun et al. 2015) that can be distilled case wise.

\subsection{Non-scientific issues that cause improper downscaling}

Besides scientific issues, a number of non-scientific aspects hamper the downscaling interface to work properly. These are not climate data or downscaling methodology specific, but are issues common in inter- and transdisciplinary projects, such as different concepts and perspectives on data, different background knowledge, and different use of languages (e.g. Eppler 2007; Strasser et al. 2014). In our view, the following three issues matter most at the 
Roessler et al. Challenges to link climate change data provision and user needs

461

462

463

464

465

466

467

468

469

470

471

472

473

474

475

476

477

downscaling interface: (a) knowledge based issues, (b) communication related issues, (c) structural issues. In the following, we elaborate each of the issues and suggest some possible ways how to tackle them:

\section{A - Knowledge Based Issues}

Issues based on divergent knowledge of actors are most obvious, most relevant and yet the hardest to solve. Trivially, if all actors would have the same common knowledge, many problems at the downscaling interface would not occur. Mutual learning is hence found to be an essential part in transdisciplinary studies in general (Pohl and Hirsch Hadorn 2008; Mobjörk 2010), but also in joint efforts of CCIAs and hence at the downscaling interface (e.g. Strasser et al. 2014). Here, we do not refer to the knowledge of actors, but more specifically to the knowledge relevant to exchange data and information at the downscaling interface (see Figure 1). However, different aspects should be taken into account for any use of modelled regional climate change data. These aspects are to our experience not always as present to impact modellers and societal users as they should be:

(1) Climate models are simplifications of real climate and suffer from substantial errors, either due to an inadequate model structure (physical processes might be missing or mis-represented) or due to unconstrained model parameters. These errors result in considerable model uncertainties from large (e.g., the representation of heatwaves in GCMs) to local scales (e.g., extreme precipitation in a downscaling method).

(2) Internal climate variability affects the estimation of biases and the projection of climate change far into the 21st century, in particular at regional scales. 
Roessler et al. Challenges to link climate change data provision and user needs

(3) The difference between the real climate and the modelled climate (a model is not the real climate and can only produce the aspects / physics of the climate that are included into the model) and the uncertainties and limitations arising when applied on a local or regional scale model.

(4) The scale discrepancy between point data and area-averaged gridded data.

(5) The missing synchrony between observed data and present simulations with free running climate models.

(6) The problem to handle an ensemble - of several equally probable times series - instead of a single time series

An increased user knowledge of these aspects might help to overcome limitations at the downscaling interface, as it results in a more targeted exchange of information about what is needed from the user, and raise understanding of what kind of data and information can and cannot be provided by downscaling methods. In turn, the above list displays some obstacles a user faces today and highlights the need for guidance along with the data or information provided.

On the other hand, climate data providers often lack knowledge on how the climate data is incorporated into impact models (e.g. undercatch correction or the spatial extrapolation of station data), what critical thresholds are and how climate information is applied in daily business. This knowledge might help climate modellers to understand the data requests better (including the need for a certain accuracy). It might also help solving some problems: if climate data providers knew more about the intended use of the data, they might be able to come up with some supportive statements about the data or with another kind of data (i.e. probability 
Roessler et al. Challenges to link climate change data provision and user needs

505

506

507

508

509

510

511

512

513

514

515

516

517

518

519

520

521

522

523

524

525

526

527

information) that might improve the usability of the climate data in impact studies or societal use.

A part of these issues might be solved by expecting all actors involved to obtain some elementary knowledge about the system of interest. This fact again calls for mutual learning as an essential part of a joint downscaling and climate change assessment. However, since all individuals participating in this exchange are experts in their own field, we cannot expect everyone to become an expert on everything. But, being humble and aware of one's own limited competence, and involving and accepting one other's expertise - although it might be difficult at first - helps to gain a common understanding and can lead to new knowledge. Within VALUE, we also made this experience.

Apart from lacking knowledge on how to improve CCIAs, a different side of the same medal is the unawareness of climate change effect at all. For instance, some research communities consider climate change as not relevant or of minor importance to their field. This lack of consideration directly affects the research results, as specific solutions for their possible future demands will be underrepresented, if not completely missing. To consider climate change as of minor importance might or might not be true. In some cases, climate change might be of minor importance compared to other stressors. It might also be of less importance when being dealt with for the next 2-3 decades, as natural variability might dominate the uncertainty for this timeframe (Hawkins and Sutton 2009). However, in many cases climate change poses at least an additional stressor to systems. For example, the tourism sector has a very limited and imbalanced knowledge about global warming impacts, and is currently considered among the economic sectors least prepared for the risks and opportunities posed by climate change (Scott 2011). Energy systems, despite being one of the key systems for social and economic 
Roessler et al. Challenges to link climate change data provision and user needs

development, frequently do not include the effects of a changing climate in their planning and operation (Schaeffer et al. 2012). On the one hand, if the relevance of climate change related impacts on their activities is not recognized by societal users, the need for CCIAs diminishes. On the other hand, if impact modellers do not address these impacts and fail to acquire and communicate this knowledge, the full linkage is jeopardized.

To overcome obstacles based on divergent knowledge that are typical in transdisciplinary projects, fewer scientific solutions are present (Hinkel 2008) than for societal or technical integration of actors. In the field of knowledge integration, Hinkel (2008) suggests to first define a common language, based on which a joint methodological concept can be developed resulting in coupled models rather than in coupled theories. The willingness of all actor groups to learn, and adapt common practices, the "societal integration"(Hinkel 2008), is a prerequisite whose importance was also highlighted by the ClipC consortium (Groot et al. 2014). To define a common language, glossaries clarifying the understanding of terms in a certain community are very helpful. Based on this a joint methodological concept can be developed. The VALUE project as well as the ClipC consortium generated such a glossary for the climate and downscaling community (http://www.clipc.eu/glossary), respectively. For the purpose of mutual learning between the actor groups at the downscaling interface, additional glossaries that have to be compiled by societal users and impact modellers for their specific field of interest are worthwhile.

In actual projects that work on the downscaling interface, e.g. for the purpose of a CCIA study, the establishment of a "task force" that elaborates a common language, common understanding and mutual knowledge very early in a project was suggested by Strasser et al. (2014). This idea is also present in several projects at the FAO (personal communication $\mathrm{H}$. Kanamura). This task 
Roessler et al. Challenges to link climate change data provision and user needs

551 force should consists of delegates from each actor group that are also responsible for the

552 outreach in their specific actor group. An advantage of this procedure lies in its smaller group

553 size and that delegates likely are more committed to the transdisciplinary process. The relevance

554 of this commitment was also one of the findings of the EUPORIAS review (Hewitt et al. 2013),

555 where the nomination of a person being responsible for the stakeholder needs was considered

556 as crucial (Groot et al. 2014). This person could be the delegate from the climate community in

557 the "task force" setting.

558 The commitment of the involved actor groups to work on the transdisciplinary interface goes

559 even further, as it demands a change in the "behaviour" of data providers and users as well.

560 Both sides need to agree on the work-sharing to tackle this issue. Table 3 shows a tentative

561 proposal of such a responsibility sharing:

562

563

\section{B - Communication related issues}

564 Climate model data as an input in impact research or decision-making must not only be 565 delivered, but also be communicated in a way the user understands and that enables the user 566 to apply the climate data and information within their own decision context. To fulfill this 567 demand, many producers of climate data and climate service providers use the internet as their 568 main outreach tool. To use this outreach channel is reasonable as it provides easy access for the 569 users to the data they request (at least theoretically, as not all data are as easily available as 570 necessary). However, a number of problems come along: 
Roessler et al. Challenges to link climate change data provision and user needs

571 (a) A great deal of data are either not available for a long time after their production to allow for 572 scientific exploitation (e.g. PRUDENCE and ENSEMBLES project), or their use is restricted to non573 commercial use.

574 (b) A large amount of data are stored in formats and indexed in climatological terms. So, from a 575 user perspective, required data are hard to find and process.

576 (c) Not all data portals provide an ingenious guidance system on the strengths and weaknesses 577 of certain data / output of certain models or methods that addresses not-climatologists and also 578 non-scientific users.

579 (d) The communication of uncertainties inherent to the climate model data is a complex 580 challenge, even more in a one-direction communication setting like webpages.

581 Thus, many users find resort to the information that is most-readily accessible instead of the 582 data that would suit their information needs best. In contrast, climate data providers may not always be interested in providing the data as "easily" as required by the users. This might be due to doubts on- be justified or not - users' awareness of the central differences between observational and model data (see section A of this subchapter). Hieroglyphic data portals enforce the users to contact the climate data providers and receive some guidance about the downloaded data - or shove potential users towards more convenient portals even if the data provided are less resilient. Another reason might be the selfconception of climate data providers as being climate scientists for which outreach is not an essential part of their duty. While it is basically true that climate change research is not

591 necessarily connected to communication issues, at least the outreach portals should be 592 developed by people who see their calling in both subjects: climatology and communication. 
Roessler et al. Challenges to link climate change data provision and user needs

593

594

595

596

597

598

599

600

601

602

603

604

605

606

607

608

609

610

611

612

613

614

Moreover, outreach and communication aspects are highly underrated by science funding agencies, as well as by the research community itself, obstructing a higher interest of scientists to develop new and hopefully better forms of communication. Certainly, this lack of outreach has been realized by founding organisations that promote the development of new, much more user-oriented portals, like ClipC, that try to combine user guidance with data provision (Groot et al. 2014). Other strategies tend to provide outreach reports along downscaled national climate change data sets, like the Swiss CH2011 project (CH2011), the French Jouzel report 2014 (Ouzeau et al. 2014), the KNMI report from the Netherlands (KNMI 2014), the SIAM report (Santos et al. 2002).

Beyond data portals, several studies proved the added value of constant direct face-to-face communication between data providers and data users for a successful downscaling product and climate change impact assessment (Almeida et al. 2015), H. Hübener, personal communication). However, an ideal communication between providers and users, if not a financed part of a project from the start, is often difficult or non-existent.

When an eventual impact of climate change on a user activity is perceived, the decision making process has to be based on the best climate information that climatologists and impact modellers can provide (Meinke et al. 2009) - it is here that several linkage problems arise. Often, climatologists do not describe in a proper manner the inherent uncertainty associated to climate projections (Burke et al. 2015), whether stemming from uncertain future emission paths, model deficiencies or internal climate variability. It is important to explain what the numbers really represent, be it observation or model results. Furthermore, uncertainties vary by variable, region, future time period and season. Every climate data provider has some notion: 
Roessler et al. Challenges to link climate change data provision and user needs

615

616

617

620

621

622

623

624

627

630

631

632

633

634

635

- of variables that are more or less reliable (e.g. temperature change information is much more reliable than precipitation),

- of the accuracy of the projection in relation to observations

- of aspects that are better- or worse-represented (e.g., extreme droughts might be better captured than extreme precipitation)

- of regions that are easier to cover than others (e.g. often mountains are more difficult than plains, or cooling in stable planetary boundary layers over plains).

To provide all kinds of users from different regions, subjects, backgrounds and interests with the information they need much more information on the (physical, empirical) reliability of each part of the data or information. In the cases when climatologists provide a bandwidth of the model results, impact modellers sometimes do not know how to consider this interval for the information they provide to users. In some cases when the bandwidth or uncertainty is accounted for in all the linkages from climatologist to user - frequently at the time of projecting climate change impacts at temporal and spatial scales pertinent for decision making - the uncertainties have increased enormously (Jones 2000). This chain of problems has as a consequence that information is often perceived as too uncertain to be of any practical use, or that there is a failure in quantifying uncertainty (Kiem et al. 2014). At this point, improved communication is needed that clearly states the robust and certain part of the projection. Reasons for the found uncertainties should be given additionally, but should not obscure the main result. Current scientific focus on uncertainties is of high relevance, but it should not prevent a clear answer (if present) to the raised societal question. 
Roessler et al. Challenges to link climate change data provision and user needs

637

638

639

640

641

642

644

645

646

650

651

652

653

654

655

656

657

\section{C - Structural issues}

Callahan et al. (1999) state, among other more technical problems (like low forecast skill, low geographic resolution), an "institutional aversion to incorporating new tools into decision making". (Lee and Whitely Binders 2010) find barriers in the form of "limited staff capacity, lack of clear guidance on how to integrate climate change into planning, lack of management support, institutional inertia, limited data availability, limited funding, lack of mandate to plan for climate change and complexity of the problem."

We add to this list some barriers at the climate data provider side of the "fence": missing or too little funding / manpower for data provision, post-processing and communication in climate research projects, too little appreciation of outreach in the scientific community and inflexible actors also at the climate data provider side. One example to illustrate the issue of postprocessing is the divergent number of simulations performed and provided in data portals as e.g. found in CORDEX simulations. With a more general focus on CCIA, a major obstacle is the less funding of comprehensive impact studies and dissemination of impact model results, as those data set are the basis for adaptation strategies.

Some of these barriers could be overcome by funding (for data post-processing and outreach, for manpower at the interface between climate data providers and users). Some might need time and dedicated fighters (more appreciation for outreach activities in the scientific community, overcoming old habits and uninterested recipients). Callahan et al. (1999) propose a combination of technical improvements and reciprocal and iterative mutual education between climate data providers and managers to overcome these barriers. 
Roessler et al. Challenges to link climate change data provision and user needs

658

659

660

661

662

663

664

665

666

667

668

669

670

671

672

673

674

675

676

677

678

679

Besides, working at the downscaling interface is not as ideal as Figure 1 might suggest. In reality it is often much more chaotic and scattered, because the overwhelming part of actors at the interface work rather independently than jointly, using data and downscaling methods they can get hold of or that they can understand and perform on their own. This more chaotic cast adds further complexity to the downscaling interface. One reason might be the missing or underdeveloped number of climate change consultancies, or "intermediaries" as described by Groot et al. (2014), that can help link the different actor group and provide guidance along the downscaling and CCIA process.

The internet portal www.climate-knowledge-hub.org collects those intermediators for Europe and shows a yet unfinished collection of approximately 180 intermediators. Private intermediators, national and regional climate service centres are crucial and independent contact points, but they are not present in every country or region and, even if so, there is still a great mismatch between climate providers and users. This is even more the case if not the climate model data itself but a tailored downscaling is needed to fulfil the user needs. And the number of users will likely drastically increase in the coming years, also due to the political willingness to foster adaptation also at the community level (COM 2013).

Still, the "number problem" - lots of users and only relatively few providers - remains. This is where new ideas and developments to overcome structural issues come into play. The national meteorological services and - if separate institutions - climate service providers (CSC) as professional "border organisations" might play a crucial role here, given they are suitably funded and aimed. For sure, they cannot themselves serve every request. CSC can be contact points that establish the first contacts between actor groups and/or accompany the downscaling 
Roessler et al. Challenges to link climate change data provision and user needs

680

681

682

683

684

685

686

687

688

689

690

691

692

693

694

695

696

697

698

699

700

701

process. The new Swiss National Climate Service Centre (NCCS) and the Climate Service Center in Germany strives this way.

Recently many different internet portals have emerged (e.g. ClipC, Copernicus, CCAFS, IPCCDDC) all claiming they incorporate climate data user's demands in a much more specific way. Several of these portals allow for on-the-fly calculation of user-tailored climate change information at the regional scale (CCAFS, Santander Downscaling Portal). Although this seems a very promising way to cope with the number problem, all concerns raised above still hold, with a very sophisticated request tool still needed on how to ensure that proper tailored information is available to users on portals/platforms (without face-2-face meetings). This remains an open question and challenge.

Another way to overcome the number problem is to establish a new profession of climate change advisors: Well trained, private consultants who can advise local authorities or other environmental offices how to access, apply and interpret downscaled climate data or information for each specific case. An example of this kind of profession might be the energy advisors, a new professional branch that is quite successful in some European countries (Owen et al. 2014). Today, some large consultancy companies offer already a climate change impact and adaptation program. But, they are hardly affordable for some communities. An essential prerequisite for such a profession would be some kind of certificate that guarantees a solid education.

\section{Conclusion}

The inter-and transdisciplinary downscaling interface is composed of numerous various actors with many backgrounds, different perspectives and diverse knowledge. This setting calls for 
Roessler et al. Challenges to link climate change data provision and user needs

702

703

704

705

706

707

708

709

710

711

712

713

714

715

716

717

718

719

720

721

722

723

solutions on an individual basis. However, while this might be the ideal case, it remains unrealistic given the vast number of CCIA. Hence, a structure of user groups and their needs, as well as a structure of issues hampering a proper downscaling, and finally a guidance of how to choose among all the present climate model data sets help to abstract from individual challenges. Furthermore, this structuring might help to foster research in a direction helpful for the different users.

We have presented here a suggestion of such a structuring of actors, needs and issues. In addition, the VALUE platform shall result in a guidance of how to select the most appropriate downscaling methodology or data for a given case study. Still, current climate models and current downscaling techniques cannot meet some user needs, and some likely cannot be met also in the near future. We think, it is also the duty of the climate providers to be clear about these limitations. In turn, the impact modellers and the societal users are responsible to develop reliable solutions for these cases. Furthermore, what can and what cannot be provided remains a fine line that has to be negotiated continuously between the three actor groups, as scientific knowledge progresses.

Apart from the data limitations, we showed that common inter- and transdisciplinary issues might hamper a proper usage of downscaling data or even the development thereof. The incorporation of established techniques to solve transdisciplinary issues have to be applied in CCIA, but will most likely be dismissed due to financial obstacles.

Finally, internet portals like ClipC or downscaling platforms are of great help to provide climate data to as much CCIA conductors as possible. Nevertheless, we doubt that those portals and guidelines will solve the great communication challenges if not a minimum of mutual - common 
Roessler et al. Challenges to link climate change data provision and user needs

knowledge is built up. Yet, international, national or even regional climate service centres are crucial to lead the optimal way, to help network building and to foster knowledge and communication among the 1st order users and providers (see Figure 1) at the downscaling interface. An increasing number of private companies - intermediaries - that advise communities or corporations in CCIA might accompany these centres. Those consultants should be regularly trained and certificated to ensure a high standard for CCIA.

Based on both, an ever-increasing disciplinary knowledge and a shared - mutual knowledge on how to work together transdisciplinarily, the partly huge challenges currently present at the downscaling interface might be tackled. This will help to provide the best possible basis for profound adaptation to climate change.

\section{Acknowledgements}

VALUE is funded via the EU FP7 programme as EU COST Action ES1102. We thank the VALUE community for their input to this perspective and review paper. We also like to thank all participants of the survey conducted.

\section{References}

Addor N, Rössler O, Köplin N, Huss M, Weingartner R, Seibert J . 2014 . Robust changes and sources of uncertainty in the projected hydrological regimes of Swiss catchments. Water Resour. Res. 50:7541-7562.

Almeida MC, Coelho PS, Rodrigues AC, Diogo PA, Maurício R, Cardoso RM, Soares PM . 2015. Thermal stratification of Portuguese reservoirs: Potential impact of extreme climate scenarios. Journal of Water and Climate Change 6:544.

Ban N, Schmidli J, Schär C . 2015 . Heavy precipitation in a changing climate: Does short-term summer precipitation increase faster? Geophys. Res. Lett. 42:1165-1172.

Bedia J, Herrera S, Gutiérrez JM . 2013 . Dangers of using global bioclimatic datasets for ecological niche modeling. Limitations for future climate projections. Global and Planetary Change 107:1-12. 
Roessler et al. Challenges to link climate change data provision and user needs

Benestad, R, Rössler, O, Hübener, H, Kanamaru, H, Bosshard Th, Vlachogianni D, Pavan V, Cardoso RM, Soares P, Szabo P, Dubrovsky M, Christodoulides P, Florides G. 2014. White paper on climate change data for end-use: Online Resource: http://www.valuecost.eu/sites/default/files/d1_enduserneeds_whitepaper.pdf.

Benestad RE . 2016. A mental picture of the greenhouse effect. Theor Appl Climatol. Benestad RE, Hanssen-Bauer I, Chen D . 2008 . Empirical-statistical downscaling. World Scientific Pub Co Inc, New Jersey.

Bergmann M, Klein JT, Faust RC . 2012 . Methods for transdisciplinary research: A primer for practice. Campus-Verlag, Frankfurt.

Boberg F, Berg P, Thejll P, Gutowski WJ, Christensen JH . 2009 . Improved confidence in climate change projections of precipitation evaluated using daily statistics from the PRUDENCE ensemble. Climate Dynamics 32:1097-1106.

Brockhaus P, Lüthi D, Schär C . 2008 . Aspects of the diurnal cycle in a regional climate model. Meteorol. Z. 17:433-443.

Burke M, Dykema J, Lobell DB, Miguel E, Satyanath S . 2015 . Incorporating Climate Uncertainty into Estimates of Climate Change Impacts. Review of Economics and Statistics 97:461-471.

Callahan B, Miles E, Fluharty D . 1999 . Policy implications of climate forecasts for water resources management in the Pacific Northwest. Policy Sciences 32:269-293.

Cash D, Clark WC . 2002 . From Science to Policy: Assessing the Assessment Process. SSRN Journal.

CH2011 Swiss Climate Change Scenarios CH2011, Zurich.

Christensen JH, Christensen OB . 2007 . A summary of the PRUDENCE model projections of changes in European climate by the end of this century. Climatic Change 81:7-30.

COM . 2013 . The EU strategy on adaptation to climate change: Strengthening Europe's resilience to the impacts of climate change.

Cuhls K . 2003 . From forecasting to foresight processes?: New participative foresight activities in Germany. J. Forecast. 22:93-111.

Déandreis C, Pagé C, Braconnot P, Bärring L, Bucchignani E, Cerff WS de, Hutjes R, Joussaume S, Mares C, Planton S, Plieger M . 2014 . Towards a dedicated impact portal to bridge the gap between the impact and climate communities: Lessons from use cases. Climatic Change 125:333-347.

Di Luca A, Elía R de, Laprise R . 2013 . Potential for small scale added value of RCM's downscaled climate change signal. Clim Dyn 40:601-618.

Di Luca A, Evans JP, Pepler A, Alexander L, Argüeso D . 2015 . Resolution Sensitivity of Cyclone Climatology over Eastern Australia Using Six Reanalysis Products*. J. Climate 28:95309549.

Eppler MJ . 2007 . Knowledge Communication Problems between Experts and Decision Makers: an Overview and Classification. The Electronic Journal of Knowledge Management 5:291-300.

Etzelmüller B, Schuler TV, Isaksen K, Christiansen HH, Farbrot H, Benestad R . 2011 . Modeling the temperature evolution of Svalbard permafrost during the 20th and 21st century. The Cryosphere 5:67-79. 
Feser F, Rockel B, Storch H von, Winterfeldt J, Zahn M . 2011 . Regional Climate Models Add Value to Global Model Data: A Review and Selected Examples. Bull. Amer. Meteor. Soc. 92:1181-1192.

Field CB, Barros VR, Dokken DJ, Mach KJ, Mastrandrea MD . 2014 . Climate Change 2014 Impacts, Adaptation, and Vulnerability. Cambridge University Press, Cambridge.

Flato G, Marotzke J, Abiodun B, Braconnot P, Chou SC, Collins W, Cox P, Driouech F, Emori S, Eyring V, Forest C, Gleckler $P$, Guilyardi E, Jakob C, Kattsov V, Reason C, Rummukainen $M$. 2013 . Evaluation of Climate Models: 9. In: IPCC . ed . Climate Change 2013: The Physical Science Basis. Contribution of Working Group I to the Fifth Assessment Report of the Intergovernmental Panel on Climate Change. Cambridge University Press, Cambridge, United Kingdom and New York, NY, USA, p 741-866.

Formayer H, Gerersdorfer T, Seiber P, Loibl W, Töglhofer A, Prettenhaler F, Töglhofer C, Köberl A, ThemeßI M, Gobiet A, Truhez H, Schleidt K, Waitz Vetter von der Lilie, W., Kroiss F, Anders I, Jurkovic A, Kaindl G . 2011 . KlimDAtZ - Konzept für ein Österreichisches Klimadaten-Zentrum Klima- und Energiefonds.

Frei C, Schöll R, Fukutome S, Schmidli J, Vidale PL . 2006 . Future change of precipitation extremes in Europe: Intercomparison of scenarios from regional climate models. J. Geophys. Res. 111.

Giorgi F, Bates GT . 1989. The Climatological skill of a regioanl model over complex terrain. Mon. Wea. Rev. 117:2325-2347.

Giorgi F, Jones C, Asrar GR . 2009 . Addressing climate information needs at the regional level: the CORDEX framework. WMO Bulletin 58.

Goodess CM . 2005 . STARDEX - downscaling climate extremes, Norwich.

Groot A, Swart R, Hygen H, Benestad RE, Cauchy A, Betgen Cauchy, Dubois G . 2014 . ClipC deliverable User requirements, part 1: Strategies for user consultation and engagement and user requirements: Synthesis from past efforts.

Haanpää S, Kerkkä V, Lamminmäki, Tanja, Holma, Anne, Kytö, Tapio . 2009 . CCCRP ilmastoportaalihankkeen käyttäjätarveselvitys ja kuntasuunnittelun apurin käytettävyysanalyysi. Climate Change Community Response Portal . CCCRP ..

Hall A . 2014 . Climate. Projecting regional change. Science . New York, N.Y. . 346:1461-1462. Hansen BB, Isaksen K, Benestad RE, Kohler J, Pedersen $\AA \varnothing$, Loe LE, Coulson SJ, Larsen JO, Varpe $\varnothing .2014$. Warmer and wetter winters: Characteristics and implications of an extreme weather event in the High Arctic. Environ. Res. Lett. 9:114021.

Hawkins E, Sutton R . 2009 . The Potential to Narrow Uncertainty in Regional Climate Predictions. Bull. Amer. Meteor. Soc. 90:1095-1107.

Hewitson BC, Daron J, Crane RG, Zermoglio MF, Jack C . 2014 . Interrogating empiricalstatistical downscaling. Climatic Change 122:539-554.

Hewitt C, Buontempo C, Newton P . 2013 . Using Climate Predictions to Better Serve Society's Needs. Eos, Transactions American Geophysical Union 94.

Hinkel J . 2008 . Transdisciplinary knowledge integration: cases from integrated assessment and vulnerability assessment. Ph.D. thesis, Wageningen University, Wageningen, The Netherlands. 
Intergovernmental Panel on Climate Change . 2014 . Climate Change 2013 - The Physical Science Basis. Cambridge University Press, Cambridge.

Jones RN . 2000 . Managing Uncertainty in Climate Change Projections - Issues for Impact Assessment. Climatic Change 45:403-419.

Kendon EJ, Roberts NM, Fowler HJ, Roberts MJ, Chan SC, Senior CA . 2014 . Heavier summer downpours with climate change revealed by weather forecast resolution model. Nature Clim. Change 4:570-576.

Kiem AS, Verdon-Kidd DC, Austin EK . 2014 . Bridging the gap between end user needs and science capability: Decision making under uncertainty. Clim. Res. 61:57-74.

KNMI . 2014 . KNMI'14: Climate Change scenarios for the 21st Century - A Netherlands perspective. KNMI.

Kotlarski S, Keuler K, Christensen OB, Colette A, Déqué M, Gobiet A, Goergen K, Jacob D, Lüthi D, van Meijgaard E, Nikulin G, Schär C, Teichmann C, Vautard R, Warrach-Sagi K, Wulfmeyer V . 2014 . Regional climate modeling on European scales: A joint standard evaluation of the EURO-CORDEX RCM ensemble. Geosci. Model Dev. 7:1297-1333.

Laprise R, Elía R de, Caya D, Biner S, Lucas-Picher P, Diaconescu E, Leduc M, Alexandru A, Separovic L . 2008 . Challenging some tenets of Regional Climate Modelling. Meteorol Atmos Phys 100:3-22.

Lee C, Whitely Binders L . 2010 . Assessing Pacific Northwest Water Resources Stakeholder Data Needs. In: Cimate Impacts Group, Center for Science in the Earth System . ed . Final Report for the Columbia Basin Climate Change Scenarios Project, Seattle.

Maraun D, Wetterhall F, Ireson AM, Chandler RE, Kendon EJ, Widmann M, Brienen S, Rust HW, Sauter T, ThemeßI M, Venema VKC, Chun KP, Goodess CM, Jones RG, Onof C, Vrac M, Thiele-Eich I . 2010 . Precipitation downscaling under climate change: Recent developments to bridge the gap between dynamical models and the end user. Rev. Geophys. 48.

Maraun D, Widmann M, Gutiérrez JM, Kotlarski S, Chandler RE, Hertig E, Wibig J, Huth R, Wilcke RA . 2015 . VALUE: A framework to validate downscaling approaches for climate change studies. Earth's Future 3:1-14.

McNie EC . 2007 . Reconciling the supply of scientific information with user demands: An analysis of the problem and review of the literature. Environmental Science \& Policy 10:17-38.

Meinke H, Howden SM, Struik PC, Nelson R, Rodriguez D, Chapman SC . 2009 . Adaptation science for agriculture and natural resource management-urgency and theoretical basis. Current Opinion in Environmental Sustainability 1:69-76.

Meredith EP, Maraun D, Semenov VA, Park W . 2015 . Evidence for added value of convectionpermitting models for studying changes in extreme precipitation. J. Geophys. Res. Atmos. 120:12500-12513.

MeteoSwiss . ed . . 2016 . Fachbericht MeteoSchweiz, Vol. 258.

Mobjörk M . 2010 . Consulting versus participatory transdisciplinarity: A refined classification of transdisciplinary research. Futures 42:866-873. 
Nikulin G, Bosshard T, Yang W, Bärring L, Wilcke R, Vrac M, Vautard R, Noel T, Gutiérrez JM, Herrera S, Fernández J, Haugen JE, Benestad R, Landgren OA, Grillakis M, loannis T, Koutroulis A, Dosio A, Ferrone A, Switanek M . 2015 . Bias Correction Intercomparison Project. BCIP .: an introduction and the first results 17.

Noblet-Ducoudré N de, Boisier J-P, Pitman A, Bonan GB, Brovkin V, Cruz F, Delire C, Gayler V, van den Hurk BJJM, Lawrence PJ, van der Molen MK, Müller C, Reick $\mathrm{CH}$, Strengers BJ, Voldoire A . 2012 . Determining Robust Impacts of Land-Use-Induced Land Cover Changes on Surface Climate over North America and Eurasia: Results from the First Set of LUCID Experiments. J. Climate 25:3261-3281.

Ouzeau G, Déqué M, Jouini M, Planton S, Vautard R . 2014 . Le climat de la France au XXle siècle - Volume 4: Scénarios régionalisés édition 2014 pour la métropole et les régions d'outre-mer. Rapports - Dierection générale de l'Énergie et du Climat.

Owen A, Mitchell G, Gouldson A . 2014 . Unseen influence-The role of low carbon retrofit advisers and installers in the adoption and use of domestic energy technology. Energy Policy 73:169-179.

Pingel S . ed . . 2012 . ICCS2: Toward a Climate Services Enterprise Conference Report.

Pohl C, Hirsch Hadorn G . 2008 . Methodological challenges of transdisciplinary research. Natures Sciences Sociétés 16:111-121.

Prein AF, Langhans W, Fosser G, Ferrone A, Ban N, Goergen K, Keller M, Tölle M, Gutjahr O, Feser F, Brisson E, Kollet S, Schmidli J, Lipzig NPM, Leung R . 2015 . A review on regional convection-permitting climate modeling: Demonstrations, prospects, and challenges. Reviews of Geophysics 53:323-361.

Rummukainen M . 2010 . State-of-the-art with regional climate models. WIREs Clim Change 1:82-96.

Santos FD, Forbes K, Moita R . 2002 . Climate Change in Portugal, Scenarios, Impacts, and Adaptation Measures - SIAM Report. Gradiva, Lisboa, Portugal.

Schaeffer R, Szklo AS, Pereira de Lucena AF, Moreira Cesar Borba BS, Pupo Nogueira LP, Fleming FP, Troccoli A, Harrison M, Boulahya MS . 2012 . Energy sector vulnerability to climate change: A review. Energy 38:1-12.

Scott D . 2011 . Why sustainable tourism must address climate change. Journal of Sustainable Tourism 19:17-34.

Shepherd TG . 2014 . Atmospheric circulation as a source of uncertainty in climate change projections. Nature Geosci 7:703-708.

Snäll T, Benestad RE, Stenseth NC . 2009 . Expected future plague levels in a wildlife host under different scenarios of climate change. Global Change Biology 15:500-507.

Strasser U, Vilsmaier U, Prettenhaler F, Marke T, Steiger R, Damm A, Hanzer F, Wilcke R, Stötter J . 2014 . Coupled component modelling for inter- and transdisciplinary climate change impact research: Dimensions of integration and examples of interface design. Environmental Modelling \& Software 60:180-187.

Swart R, Avelar D . eds . . 2011 . Bridging Climate Research Data and the Needs of the Impact Community: Proceedings of the IS-ENES/EEA/CIRCLE-2 Workshop. 
Roessler et al. Challenges to link climate change data provision and user needs

Takayabu I, Kanamaru H, Dairaku K, Benestad RE, Storch H von, Christensen JH . 2016. Reconsidering the Quality and Utility of Downscaling. Journal of the Meteorological Society of Japan 94A:31-45.

van der Linden P, Mitchell J . 2009 . ENSEMBLES: Climate Change and its Impacts: Summary of research and results from the ENSEMBLES project. Met Office Hadley Centre, FitzRoy Road, Exeter EX1 3PB, UK, Exeter.

Wang C, Zhang L, Lee S-K, Wu L, Mechoso CR . 2014 . A global perspective on CMIP5 climate model biases. Nature Climate Change 4:201-205.

Woollings T . 2010 . Dynamical influences on European climate: an uncertain future. Philosophical transactions. Series A, Mathematical, physical, and engineering sciences 368:3733-3756.

Zubler EM, Fischer AM, Fröb F, Liniger MA . 2015. Climate change signals of CMIP5 general circulation models over the Alps - impact of model selection. Int. J. Climatol.:n/a-n/a.

Tables:

Table 1: Overview over existing internet portals to provide climate data, be it observations, climate model data, onthe-fly-downscaled data or climate derivatives like indices.

\begin{tabular}{|c|c|c|c|c|c|c|c|c|}
\hline \multicolumn{2}{|c|}{ Climate data portal } & Internetseite & observations & $\mathrm{GCM}$ & RCM & incl. Downscaling & Climate Indecies & Comments \\
\hline \multicolumn{9}{|c|}{ Supranational portals } \\
\hline & ClipC & http://www.clipc.eu/home & & $\mathrm{x}$ & & & $\mathrm{x}$ & \\
\hline & Downscaling Portal & https://www.meteo.unican.es/downscaling/intro & $\mathrm{x}$ & & $\mathrm{x}$ & $x$ & & \\
\hline & ECAD & http://www.ecad.eu & $\mathrm{x}$ & & & & & \\
\hline & CORDEX & http://www.cordex.org/ & & & $\mathrm{x}$ & & & \\
\hline & ENES & https://verc.enes.org/ & & $\mathrm{x}$ & $\mathrm{x}$ & & & \\
\hline & ESGF & esgf.IInl.gov & $\mathrm{x}$ & $\mathrm{x}$ & $\mathrm{x}$ & & & \\
\hline & Copernicus & http://climate.copernicus.eu/ & & & & & & \\
\hline & CCAFS & http://www.ccafs-climate.org/ & $\mathrm{x}$ & $\mathrm{x}$ & & $\mathrm{x}$ & & \\
\hline & WorldBank & http://sdwebx.worldbank.org/climateportal/ & & $\mathrm{x}$ & & $\mathrm{x}$ & & $\begin{array}{l}\text { climate } \\
\text { information }\end{array}$ \\
\hline & ENSEMBLES & http://ensemblesrt3.dmi.dk/ & & & $\mathrm{x}$ & & & \\
\hline & PRUDENCE & http://ensemblesrt3.dmi.dk/ & & & $\mathrm{x}$ & & & \\
\hline & Impact2c & www.atlas.impact $2 c . e u$ & & $\mathrm{x}$ & $x$ & & $\mathrm{x}$ & \\
\hline \multicolumn{9}{|c|}{ National portals } \\
\hline Austria & CCCA & https://www.ccca.ac.at/en/datenportal/ & $x$ & & & $x$ & & $\begin{array}{l}\text { Bias } \\
\text { corrected } \\
\text { RCM }\end{array}$ \\
\hline Australia & CSIRO & www.climatechangeinaustralia.gov.au/en & & $\mathrm{x}$ & $\mathrm{x}$ & $\mathrm{x}$ & $\mathrm{x}$ & \\
\hline Canada & $\mathrm{PCIC}$ & www.pacificclimate.org & $\mathrm{x}$ & $\mathrm{x}$ & & $\mathrm{x}$ & & \\
\hline Finland & Climate Guide & www.ilmasto-opas.fi/en & & & & & & \\
\hline France & DRIAS & www.drias-climate.fr & & & $\mathrm{x}$ & $\mathrm{x}$ & $\mathrm{x}$ & \\
\hline Portugal & Portal do Clima & www.portaldoclimae.pf/en & & & & & & \\
\hline Switzerland & C2SM & www.ch2011.ch & & $\mathrm{x}$ & $\mathrm{x}$ & $\mathrm{x}$ & $\mathrm{x}$ & \\
\hline UK & UKCIP & www.ukclimateprojections.metoffice.gov.uk & $\mathrm{x}$ & $\mathrm{x}$ & & $\mathrm{x}$ & & \\
\hline us & DCHP & http://gdo-dcp.ucllnl.org/downscaled_cmip_projections & $\mathrm{x}$ & $\mathrm{x}$ & & $\mathrm{x}$ & & \\
\hline us & USGS & http://cida.usgs.gov/climate/derivative & & $\mathrm{x}$ & & $\mathrm{x}$ & $\mathrm{x}$ & \\
\hline us & $\begin{array}{l}\text { MACA Statistical } \\
\text { Downscaling }\end{array}$ & maca.northwestknowledge.net & & $x$ & & $x$ & & \\
\hline us & CalAdapt & cal-adapt.org & $\mathrm{x}$ & $\mathrm{x}$ & & $\mathrm{x}$ & & \\
\hline
\end{tabular}


Roessler et al. Challenges to link climate change data provision and user needs

Table 2: User's key variables, required accuracy, and their spatial and temporal resolution; based on VALUE questionnaire with 62 participants. Blue numbers indicate responses of participants that are societal users from the non-water sectors. Multiple choices allowed.

\begin{tabular}{|c|c|c|c|c|c|c|}
\hline \multicolumn{7}{|c|}{ paramater and accuracy needed } \\
\hline \multirow[b]{2}{*}{ temperature } & \multicolumn{2}{|c|}{ key variable } & \multicolumn{2}{|c|}{ accuracy } & \multicolumn{2}{|c|}{ I don't know } \\
\hline & $96 \%$ & $84 \%$ & "士 5\%" & « 10-20\%" & $20 \%$ & $28 \%$ \\
\hline precipitation & $98 \%$ & $92 \%$ & $« \pm 10 \% "$ & « 10-50\%" & $17 \%$ & $25 \%$ \\
\hline wind speed & $67 \%$ & $67 \%$ & «20\%" & $« \pm 10-20 \% "$ & $41 \%$ & $45 \%$ \\
\hline rel humidity & $55 \%$ & $25 \%$ & $« \pm 10 \% "$ & $« \pm 5-20 \% "$ & $48 \%$ & $67 \%$ \\
\hline global radiation & $54 \%$ & $25 \%$ & $« \pm 5 \% "$ & «10-20\%" & $43 \%$ & $70 \%$ \\
\hline other & $30 \%$ & $25 \%$ & « 10\%" & « $\pm 10-20 \% "$ & $58 \%$ & $75 \%$ \\
\hline
\end{tabular}

spatial resolution needed

\begin{tabular}{lcc|cc|cc|cc}
\hline & \multicolumn{2}{c}{ point scale } & \multicolumn{2}{c}{$<1 \mathrm{~km}$} & \multicolumn{2}{c}{ aggregated } & \multicolumn{2}{c}{ I don't know } \\
temperature & $17 \%$ & $27 \%$ & $38 \%$ & $27 \%$ & $13 \%$ & $18 \%$ & $0 \%$ & $0 \%$ \\
precipitation & $19 \%$ & $25 \%$ & $45 \%$ & $16 \%$ & $13 \%$ & $33 \%$ & $0 \%$ & $0 \%$ \\
wind speed & $10 \%$ & $36 \%$ & $29 \%$ & $18 \%$ & $10 \%$ & $9 \%$ & $13 \%$ & $0 \%$ \\
rel humidity & $9 \%$ & $33 \%$ & $30 \%$ & $22 \%$ & $9 \%$ & $0 \%$ & $18 \%$ & $22 \%$ \\
global radiation & $11 \%$ & $33 \%$ & $25 \%$ & $11 \%$ & $11 \%$ & $0 \%$ & $18 \%$ & $22 \%$ \\
other & $12 \%$ & $25 \%$ & $33 \%$ & $0 \%$ & $12 \%$ & $12 \%$ & $21 \%$ & $25 \%$
\end{tabular}

temporal resolution needed

\begin{tabular}{|c|c|c|c|c|c|c|c|c|}
\hline \multirow[b]{2}{*}{ temperature } & \multicolumn{2}{|c|}{ hourly } & \multicolumn{2}{|c|}{ daily } & \multicolumn{2}{|c|}{ > daily } & \multicolumn{2}{|c|}{ I don't know } \\
\hline & $33 \%$ & $9 \%$ & $58 \%$ & $73 \%$ & $10 \%$ & $18 \%$ & $0 \%$ & $0 \%$ \\
\hline precipitation & $38 \%$ & $17 \%$ & $55 \%$ & $75 \%$ & $8 \%$ & $8 \%$ & $0 \%$ & $0 \%$ \\
\hline wind speed & $38 \%$ & $28 \%$ & $47 \%$ & $55 \%$ & $4 \%$ & $18 \%$ & $11 \%$ & $9 \%$ \\
\hline rel humidity & $30 \%$ & $0 \%$ & $49 \%$ & $55 \%$ & $5 \%$ & $45 \%$ & $17 \%$ & $33 \%$ \\
\hline global radiation & $25 \%$ & $0 \%$ & $54 \%$ & $44 \%$ & $7 \%$ & $45 \%$ & $15 \%$ & $33 \%$ \\
\hline other & $25 \%$ & $13 \%$ & $54 \%$ & $50 \%$ & $0 \%$ & $38 \%$ & $21 \%$ & $37 \%$ \\
\hline total number o & ants & $=62)$ & $\begin{array}{l}\text { answe } \\
\text { impac }\end{array}$ & $\begin{array}{l}\text { s of pa } \\
\text { mode }\end{array}$ & $\begin{array}{l}\text { ants th } \\
r \text { from }\end{array}$ & $\begin{array}{l}\text { t aren't } \\
\text { he wat }\end{array}$ & $r(n=12$ & \\
\hline
\end{tabular}




\section{Roessler et al. Challenges to link climate change data provision and user needs}

Table 3: Tentative proposal of a change in behaviour of actors at the downscaling interface

\begin{tabular}{|c|c|}
\hline Climate model data provider: & Climate model data / information user: \\
\hline $\begin{array}{l}\text { Be brave! Provide model output data at the (highest) } \\
\text { native temporal and spatial model resolution to expert } \\
\text { users. This might e.g. include providing values for specific } \\
\text { landscapes (like upper Rhine valley). Such an open data } \\
\text { policy requires detailed guidance and co-exploration of the } \\
\text { further analyses with the data providers. }\end{array}$ & $\begin{array}{l}\text { Be careful! Check for analogues in the research area that might be useful } \\
\text { for inter- or extrapolating climate model data for the requested } \\
\text { temporal and spatial scale. }\end{array}$ \\
\hline $\begin{array}{l}\text { Be brave! Refuse from providing implausible data, just } \\
\text { because the user asks for it. Be aware of your responsibility } \\
\text { for subsequent adaptation decisions, which rely on the } \\
\text { quality of the data provided. }\end{array}$ & $\begin{array}{l}\text { Be careful! Not every user need can be distilled from climate model } \\
\text { data. Be brave and think of alternative ways. }\end{array}$ \\
\hline $\begin{array}{l}\text { If absolutely necessary: provide bias-adjusted model } \\
\text { output. Bias correction may induce considerable artefacts } \\
\text { and expert knowledge on both the corrected climate } \\
\text { model and the considered climate is required to avoid } \\
\text { misleading interpretation. This holds in particular for } \\
\text { quantile mapping and even more sophisticated } \\
\text { approaches. }\end{array}$ & $\begin{array}{l}\text { Train your impact model / research method / decision support tool on } \\
\text { working with relative change values (compared to observations) instead } \\
\text { of absolute values if feasible. }\end{array}$ \\
\hline $\begin{array}{l}\text { If the requested data simply cannot be delivered with good } \\
\text { consciousness: try to find variables that might be useful for } \\
\text { the planned impact research or decision support and that } \\
\text { could be provided with higher confidence. }\end{array}$ & $\begin{array}{l}\text { Develop assessment tools in your specific research area } \\
\text { (e.g. assessment of critical levels that might or might not be exceeded by } \\
\text { future climate), which are able to cope with the kind of data that can } \\
\text { usually be provided with good consciousness from the climate model } \\
\text { data providers (like e.g. probabilities of exceeding certain thresholds in } \\
\text { the future). }\end{array}$ \\
\hline
\end{tabular}

